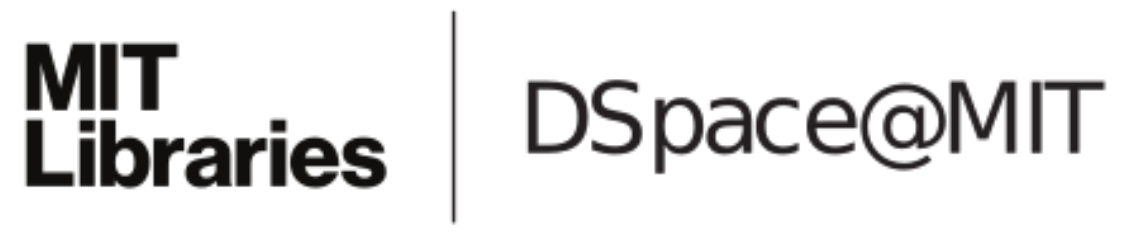

\author{
MIT Open Access Articles
}

A modal ambiguity in for-infinitival relative clauses

The MIT Faculty has made this article openly available. Please share how this access benefits you. Your story matters.

Citation: Hackl, Martin, and Jon Nissenbaum. "A Modal Ambiguity in For-infinitival Relative Clauses." Natural Language Semantics 20.1 (2011): 59-81. Web. 27 June 2012. ( Springer Science+Business Media B.V. 2011

As Published: http://dx.doi.org/10.1007/s11050-011-9075-9

Publisher: Springer-Verlag

Persistent URL: http://hdl.handle.net/1721.1/71222

Version: Author's final manuscript: final author's manuscript post peer review, without publisher's formatting or copy editing

Terms of use: Creative Commons Attribution-Noncommercial-Share Alike 3.0 


\title{
A Modal Ambiguity in For-Infinitival Relative Clauses
}

\author{
Martin Hackl and Jon Nissenbaum ${ }^{\mathrm{b}}$ \\ Department of Linguistics and Philosophy, MIT \\ Department of Languages, Literatures, and Linguistics, Syracuse University \\ ACCEPTED FOR PUBLICATION WITH MAJOR REVISIONS IN NLS \\ REVISED VERSION SUBMITTED SEPTEMBER 10, 2010
}

\begin{abstract}
This squib presents two puzzles related to an ambiguity found in For-infinitival relative clauses (FIRs). FIR's always receive a modal interpretation even in the absence of any overt modal verb, and the modal interpretation seems to come in two distinct types, which can be paraphrased by finite relative clauses employing, respectively, the modal auxiliaries should and could. The two puzzles presented here concern the compositional analysis of FIRs. Both puzzles arise from the fact that the availability of the two readings is constrained by factors that are not otherwise known to affect the interpretation of a relative clause. Specifically, we show, first, that "strong" determiners require the FIR to be interpreted as a $S H O U L D$-relative while "weak" determiners allow both interpretations (the Determiner-Modal Generalization). Secondly, we observe that the COULD-interpretation requires a raising (internally headed) structure for the FIR, while the SHOULD-interpretation is compatible with either a raising or a more standard matching (externally headed) structure (the Raising/Matching Generalization).
\end{abstract}

Key words: Relative Clause, Modality, Infinitival Clauses, Quantification

\section{For-Infinitival Relative Clauses}

For-Infinitival Relative clauses (FIRs), exemplified in (1), are non-subject relative clauses whose tense head is, as the name suggests, realized by the infinitival to and whose subject position can optionally be realized by an overt DP introduced by for.

(1) Mrs. Schaden found many things (for us) to do.

FIRs appear to invariably receive modal interpretations with a range of meanings that are all centered around goals, desires, obligations, and the like ("bouletic" or "deontic"). ${ }^{1}$ Within this range of meanings, FIRs seem to come in two distinct sub-varieties, which differ notably in their modal force. The two readings can be brought out by means of contextual factors governing the

\footnotetext{
${ }^{1}$ See Kjellmer (1975). Note that subject-gap infinitival relatives (which are incompatible with for) differ from FIRs in a number of respects, not least in having non-modal interpretations available. For instance, the subject-gap relative in (i) has a straight realis interpretation, paraphraseable as "the last person who saw Jones alive". In contrast, the FIR in (ii) can only get a modal interpretation, e.g. "the last person that we should/could see".

(i) the last person to see Jones alive

(ii) the last person (for us) to see
} 
particular set of goals or desires with respect to which the FIR is interpreted. We illustrate this in (2) employing two different if-conditionals, which signal distinct conversational backgrounds (Kratzer 1978, 1981).

(2) a. Mrs. Schaden found many things for us to do if we want to have a good time. ... many things that we could do (to achieve the goal of having a good time)

b. Mrs. Schaden found many things for us to do if we want a good grade. ... many things that we should do (to achieve the goal of getting a good grade)

As suggested by the paraphrases in (2), the two interpretations of the FIR can be characterized in terms of achieving a goal that is salient in the discourse and referenced in the if-clause. In (2)a, the goal is to have a good time. Mrs. Schaden has found helpful ideas (things that seem enjoyable to do). We could do one of them or all of them, or even find something entirely different to do and still achieve our goal of having a good time. In (2)b, the goal is to receive a good grade in Mrs. Schaden's class. Here Mrs. Schaden provides us with a list of requirements and to achieve our goal, we have to do all of the many things that she has come up with. Concomitant with the difference in goals, we note a switch in the modal force of the FIR. In (2)a, the FIR can be faithfully paraphrased with a finite relative clause that employs an existential modal such as could while in (2)b, the paraphrase features the universal modal should. Within possible world semantics we might describe the two interpretations, then, in terms of existentially and universally quantified formulas that are restricted by a bouletic accessibility relation, $R_{b}$, to worlds in which a contextually salient set of goals are met, (3). ${ }^{2}$

\section{(3) a. For many $x$ : Mrs. Schaden found $x \& \exists w^{\prime}\left[w R_{b} w^{\prime} \&\right.$ we do $x$ in $\left.w^{\prime}\right]$ \\ b. For many $x$ : Mrs. Schaden found $x \& \forall w^{\prime}\left[w_{b} w^{\prime} \rightarrow\right.$ we do $x$ in $\left.w^{\prime}\right]$}

The formula in (3)a describes fairly weak truth-conditions. It states that there are many things $\mathrm{x}$ such that it is possible for us to achieve our goals and also do x. (3)b, on the other hand, states that there are many things $\mathrm{x}$ such that it is necessary for us to do $\mathrm{x}$ in order to achieve our goals. ${ }^{3}$

\footnotetext{
${ }^{2}$ As many researchers have noticed, for-infinitivals have a future orientation (Bresnan 1972, Stowell 1982, Pesetsky 1992). We think that this is due to the fact that bouletic modality is inherently future oriented, i.e. $R_{b}$ makes only worlds accessible that are "future developments" of the world of evaluation. See Portner $(1992,1997,2009)$ and von Fintel \& Iatridou (2007) among others for discussion.

${ }^{3}$ In fact, the truth-conditions stated in (3)a seem too weak to faithfully represent the COULD-reading, which might be better approximated by (i). The latter contains a universal formula in which the restrictor and nuclear scope of the modal operator are "switched". (i) states that there are many things such that if we do them, we will achieve our goals.
}

(i) For many $x$ : Mrs. Schaden found $x \& \forall w^{\prime}\left[w e\right.$ do $x$ in $\left.w^{\prime} \rightarrow w_{R b w}^{\prime}\right]$

Note that (i) does not imply that doing (any of) the things that Mrs. Schaden found is the only way of achieving our goals, which makes it considerably weaker than (3)b. It does, however, say that if we do one of these things we will achieve our goals, which is stronger than the claim that doing $\mathrm{x}$ is consistent with achieving our goal, as (3)a states. Since we do not attempt in this squib to derive the meanings of the FIR, we will stick to the weaker version. However, we suspect that an explanation for the two puzzles we present might hinge on the choice (and more specifically on the way the correct truth conditions for this reading are derived). We note in this connection that Bhatt (2006) proposes a semantics for infinitival questions which combines the formulae in (i) and (3)a, and (responding to an earlier incarnation of this squib) he uses this semantics as part of an explicit attempt to account for 
Since each $\mathrm{x}$ is such that only worlds in which we do $\mathrm{x}$ are worlds in which we achieve our goals, we have to do all of them if we want to achieve our goal.

Throughout the squib we will refer to these two interpretations as COULD- and SHOULDreadings. Our puzzles concern the availability of these two interpretations. We observe that the COULD-reading is constrained by properties of its immediate syntactic environment (Section 2) as well as the internal organization of the FIR (Section 3) while the SHOULD-reading is not. ${ }^{4} \mathrm{We}$ note, moreover, that the finite counterparts of FIRs, which employ overt modal operators such as could and should, are not subject to any of these constraints, indicating that the infinitival nature of FIRs contributes in an essential way to the puzzle.

\section{A Correlation between Modal Force and Determiner Strength}

We have seen that FIRs can, in principle, have either a COULD- or a $S H O U L D$-interpretation and that contextual factors might make one reading more salient than the other. In the present section, we observe that the availability of the two readings interacts in a quite surprising way with the semantic properties of the determiner of the DP hosting the infinitival relative. Specifically, we will show that the generalization stated in (4), which we will refer to as the Determiner-Modal Generalization, (DMG) holds.

\section{DETERMINER MODAL GENERALIZATION (DMG):}

Strong determiners (and strong interpretations of weak determiners) always induce a SHOULD-reading in for-infinitival relative clauses. Weak interpretations of weak determiners allow both COULD- and SHOULD-readings. ${ }^{5}$

\subsection{The Basic Correlation}

To see a first illustration of the DMG, consider the contrast in (5). The examples in (5)a all use weak determiners and, as suggested by the paraphrases, allow both a COULD- and a SHOULDinterpretation. In the examples in (5)b, on the other hand, the FIRs are hosted by DPs projected from strong determiners. Unlike the examples in (5)a, they allow only the SHOULD-reading of the FIR; in all of these cases John has to play against the men if he wants to achieve some goal that is salient in the discourse (e.g. prove himself as a good player).

(5) a. A/many/a few/three/more than three/at most three/sm/etc. men (for John) to play against is/are in the next room. ${ }^{6}$

A/many/a few/three/more than three/at most three/sm/etc. men that John could/should play against is/are in the next room .

\footnotetext{
the first of the puzzles that we present here. We think that Bhatt's proposal is an intriguing, if partial, way of thinking about the two readings.

${ }^{4}$ In order to fully appreciate the empirical generalizations we will present, it is important to make sure that the examples are unambiguously FIRs, rather than instances of the superficially similar VP-adjoined purpose clause construction (e.g. I brought the book (along) for you to read). See Faraci (1974), Bach (1982), Jones (1985), Huettner (1989).

${ }^{5}$ The distinction between weak and strong determiners goes back to Milsark $(1974,1977)$ who used the familiar classification given by the "there-construction test" to categorize determiners.

${ }^{6}$ We use $s m$ to refer to the phonologically reduced (accentless) version of some.
} 
b. The/neither/every/both/most/etc. men (for John) to play against are in the next room. The/neither/every/both/most/etc. men that John should play against are next in the next room.

One can create particularly striking instances of the DMG if a given context or world knowledge is compatible only with one reading and induces oddness under the other. Since the differences between the two readings can be rather subtle, we will use such a setup throughout the paper. Consider the sentences in (6) as an instructive example.

(6) Context: From time to time Norman would think about marrying and starting a family. On such occasions, he would visit his sister, where, more often than not, several new women for him to marry would be among the house guests. His sister would then arrange it so that, at some point during the evening,

a. ... at least one new woman for him to marry would be in the kitchen. At least one woman that he could marry would be in the kitchen.

b. ... \# \#ach new woman for him to marry would be in the kitchen. Each new woman that he should marry would be in the kitchen.

The pragmatics of these examples are such that the SHOULD-reading induced by the strong determiners, (6)a, is sensible only if Norman plans to be polygamous. Weak determiners, as in (6)b, do not give rise to this effect, because they permit a COULD-interpretation, which is pragmatically available: there is nothing odd about a desire for someone to marry (possibly) one among a list of candidates.?

\subsection{Ambiguous Determiners}

It is well-known that weak determiners are ambiguous between a weak and a strong construal and that environmental factors determine which construal is present. ${ }^{8}$ Since we do not have any new insight regarding the "weak" and "strong" distinction to offer here, we simply follow Diesing (1992) among others in assuming that a DP that is interpreted in a raised position at LF is projected from a strong determiner. ${ }^{9}$ To further illustrate the DMG we show, then, that

\footnotetext{
${ }^{7}$ We know of one class of potential counter-examples to the DMG, namely FIRs whose head NP receives an instrument role within the relative, as illustrated in (i). These FIRs seem to get could-readings despite having strong determiners.

(i) a. Every pen $(*$ for me) to write with is in the top desk drawer.

b. All the cash to buy books with (has been spent already)

c. Three of the charts to do your homework with (are in the back of the book)

d. Most guns to shoot quail with (have wooden handles)

While we do not fully understand why this class is exceptional, we suspect the answer has to do with the fact that instruments are characterized by having (an intended or de facto) purpose. As such, the salient ordering source is not bouletic. If so, something like the universal modal statement that characterizes should-readings of FIRs is actually a viable candidate for the meanings of (i) after all. (e.g., "For every pen $\mathrm{x}$ such that one writes with $x$ in all of the worlds that are compatible with $x$ 's intended purpose (i.e. the pen is used in its intended manner), $\mathrm{x}$ is on the table".)

${ }^{8}$ See Diesing (1992), McNally \& Van Geenhoven (1998) among others for discussion.

${ }^{9}$ This could be derived from the assumption that only DPs that are predicative can be interpreted in their base position inside the VP, see e.g. Van Geenhoven (1998).
} 
environments that govern the distribution of strong and weak determiners also govern the availability of COULD- and SHOULD-readings of FIRs. Specifically, we show that environments that are known to allow only strong readings of weak determiners also allow only SHOULDreadings, (2.2.1), while environments that allow only weak interpretations of weak determiners allow both readings, (2.2.2).

\subsubsection{Strong Readings of Weak Determiners Allow Only SHOULD-Readings of FIRs}

A. Individual vs. Stage-Level Predicates: Indefinite subjects of individual-level predicates are known to receive only strong interpretations (Milsark 1974, Diesing 1992, Kratzer 1995). The DMG leads us to expect that FIRs modifying such subjects are limited to SHOULD-readings. The contrast in (7) suggests that this expectation is indeed borne out.

(7) a. Several/many/a few women (for Norman) to marry are learning French.

Several/many/a few women that Norman could /\#should marry are learning French.

b. \# Several/many/a few women (for Norman) to marry know French.

Several/many/a few women that Norman eold/\#should marry know French.

The oddness of (7)b indicates that the COULD-reading (which would have been sensible) is not available for FIRs that modify subject of individual level predicates such as know French. The SHOULD-reading is available but is odd for the same reason that (6)b is. In contrast, the FIR in (7)a modifies the subject of the stage-level predicate currently learning French. As such, it is felicitous because the COULD-reading is available.

B. Positive-Polarity some: Positive polarity items like some necessarily take scope over clausemate negation. Since taking scope over not brings a PPI-indefinite out of the scope of existential closure, the weak interpretation of the indefinite is unavailable in negated clauses. Combining these considerations with the DMG, we are led to expect that only a $S H O U L D$-reading will be possible for a FIR modifying a some-DP in a negated clause. A simple, non-polarity indefinite is, in contrast, predicted to have both options. This expectation is borne out by the contrast in (8). While (8)a can be understood as asserting the lack of availability of anyone that I can marry, (8)b seems to imply the existence of someone whom I am supposed to marry.

(8) a. A person (for me) to marry doesn't exist.

A person that I could/should marry doesn't exist.

b. \# Someone (for me) to marry doesn't exist.

Someone that I eould/should marry doesn't exist.

C. Reconstruction into Infinitival versus Small Clauses: Williams (1983) observed that an infinitival complement of seem allows scope reconstruction of an indefinite subject, whereas a small clause complement doesn't. ${ }^{10}$ The unavailability of reconstruction in the latter case implies that a raised small clause subject is necessarily interpreted in a derived position and, thus, given the characterization of the weak/strong distinction, DPs that allow in principle both a weak and

\footnotetext{
${ }^{10}$ See Johnson\&Tomioka (1998) for discussion.
} 
strong construal are necessarily strong in this environment. The DMG thus leads us to expect that the COULD-reading of an FIR will be unavailable if seem takes a small clause complement but not if it takes an infinitival complement. The contrast in (9) suggests that this is indeed the case.

(9) a. Three hotels (for us) to stay at tonight seem to be pretty full.

Three hotels that we could/\#should stay at tonight seem to be pretty full.

b. \# Three hotels (for us) to stay at tonight seem pretty full.

Three hotels that we eould/\#should stay at tonight seem pretty full.

(9)b is quite odd. It conveys that we ought to stay at three hotels, each of which is pretty full. (9)a, on the other hand, is perfectly felicitous (if we imagine a list of hotels under consideration) and simply conveys that three hotels we could stay at are pretty full.

\subsubsection{Weak Readings of Weak Determiners Allow both COULD- and SHOULD-Interpretations}

In the previous sub-section we observed that environments that impose "strong" interpretations on weak quantifiers disallow the COULD-reading of an FIR associated with such a quantifier. Here we show that environments that impose a "weak" interpretation on a weak quantifier allow both readings.

A. There-construction: Weak interpretations of weak determiners are forced in the "thereconstruction" (Milsark 1974 and much subsequent work). The data in (10), which again employ two different if-conditionals to bring out the two readings, indicate that FIRs that modify weak indefinites appearing in the existential there-construction allow both readings of FIRs.

(10) a. There are several/many/a few/etc. problems (for you) to write about if you are looking for an interesting topic.

There are several/many/a few/etc. problems that you could write about ...

b. There are several/many/a few/etc. problems (for you) to write about if you want your book to be the authoritative source on the topic.

There are several/many/a few/etc. problems that you should write about ...

B. Possessive have: The complement of possessive have, just like the coda position of the existential there construction, is not capable of hosting strong quantifiers, as illustrated in (11)a. Indefinites, on the other hand, can serve as complements of possessive have but receive a weak interpretation, (11)b. ${ }^{11}$ With this in mind, the data in (12) show, again, that a FIR modifying a weak indefinite can have $S H O U L D$ - and COULD-readings.

(11) a. *The deceased has every/each/most/etc. heir(s) in my hometown.

b. The deceased has many/several/three/etc. heirs in my hometown.

(12) a. The deceased has many heirs for us to talk to about suing the tobacco company. The deceased has many heirs that we could talk to about suing the tobacco company.

${ }^{11}$ See Freeze (1992) and Iatridou (1996) among others. 
b. The deceased has many heirs for us to console (so we'd better get started) The deceased has many heirs that we should console, so we'd better get started.

These data show that optionally weak determiners license a COULD-interpretation only when they receive a weak interpretation. From this it is clear that it is a property of the weak reading itself and not a simple feature of the class of determiners that can have weak readings that allows the COULD-reading. Thus, an explanation for the ambiguity of FIRs must be sensitive to the properties of the environment that drive the distinction between weak and strong determiners.

What makes the DMG especially unexpected is the fact that determiners are not known to interact with quantificational elements (in particular modal operators) inside a relative clause in this way. ${ }^{12}$ To see this, we only need to look at the finite counterparts of our FIRs. That is, even though finite relatives with overt modals have readings that seem to be exact paraphrases of forinfinitival relatives, they do not display any such dependency. In particular, strong determiners are perfectly acceptable with an existential modal inside a finite relative clause:

(13) Every/most/several of the topics that you could write about are on page four.

In other words, there is nothing inherent to determiner strength or to modal force that should result in a dependency such as the DMG. Moreover, the standard compositional treatment of determiners and relative clauses provides no direct way in which the two could interact. Determiners take NPs as arguments and quantify over entities that satisfy the property denoted by the NP. Relative clauses are NP adjuncts, which combine with the NP intersectively and simply narrow the domain of quantification.

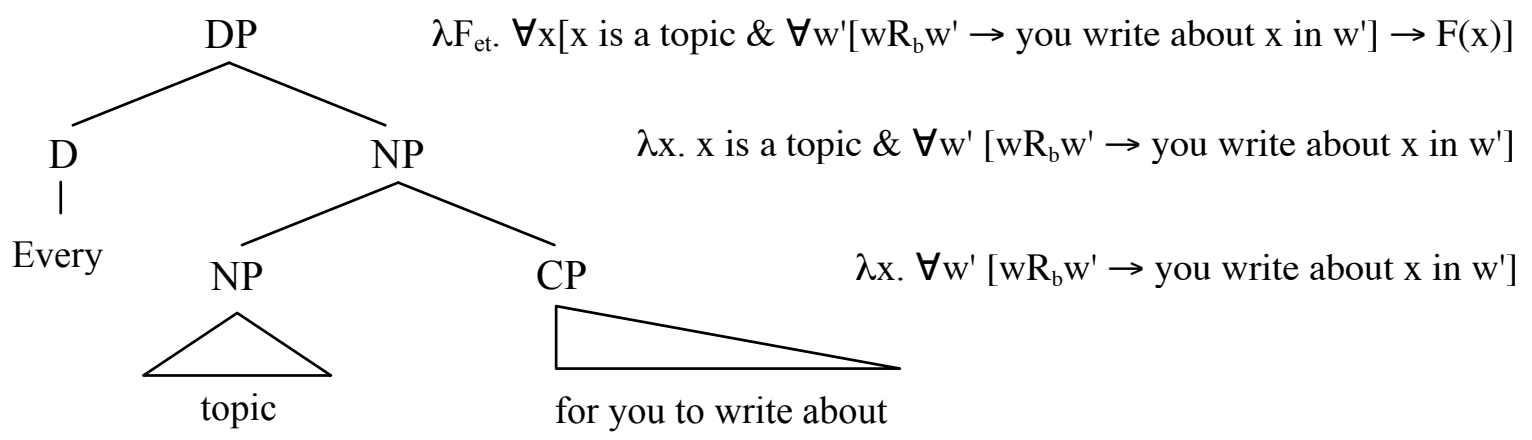

That the quantifier is able to influence how the narrowing is to be done (i.e. by enforcing the use of a universal or an existential modal predicate) is therefore puzzling and presents a challenge to the compositional analysis of determiners and/or relative clause integration. The task, then, is to identify what it is about the modal dimension of FIRs and the way they are combined with their host DP such that they gives rise to the DMG.

\footnotetext{
${ }^{12}$ The DMG is somewhat reminiscent of the constraint that only "maximality-preserving" determiners can project DPs that host amount relative clauses (Grosu \& Landman 1998). Additionally, see Koster-Moeller\&Hackl(2008) for an argument that determiners can interact scopally with operators inside the relative clause that they host. However, both of these interactions, though puzzling in their own right, are of a different type from the DMG.
} 


\section{A Correlation between Modal Force and Raising/Matching structures of FIRs}

In this section, we discuss a second unexpected constraining factor for the two readings of FIRs. We show, specifically, that the COULD-reading of an FIR is available only if the head NP is interpreted inside, rather than external to, the FIR. That implies that the FIR has a raising structure. We summarize this in (15) and refer to it as the "Raising/Matching Generalization, (RMG)."

\section{RAISING/MATCHING GENERALIZATION (RMG):}

For an FIR to make a COULD-interpretation available, it needs to have a raising structure, and cannot be adjoined to a matching external NP. SHOULD-interpretations, on the other hand, are compatible with both a raising and a matching structure.

To set the stage, we take, following a long tradition of work on relative clauses, "reconstruction" (connectivity) effects such as the ability to bind an anaphor, as in (16)a, to indicate the availability of an internally headed ("raising") structure, sketched in (17)a, in which the NP that is modified by the relative clause originates inside the relative clause (Carlson 1977, Sauerland 1998, Bhatt 2002, Hulsey \& Sauerland 2006; cf. also Kayne 1994, Vergnaud 1974, Williamson 1987). ${ }^{13}$ The absence of a Condition $\mathrm{C}$ effect, exemplified in (16)b, on the other hand, indictes the availability of a "matching" structure in which the relative clause modifies a relative-clause-external NP. ${ }^{14}$

(16) a. Mary looked at every picture of himself $\mathrm{i}_{\mathrm{i}}$ that $\mathrm{John}_{\mathrm{i}}$ sent.

b. Mary looked at every picture of John ${ }_{i}$ that he ${ }_{i}$ sent.

$$
\begin{aligned}
& \text { a. ... every }\left[_{\text {ReL.CLAuse }}\left[\cdots_{\text {INTERNAL NP }} \text { picture of himself } f_{\mathrm{i}}\right]_{\mathrm{j}} \text { that } \mathrm{John}_{\mathrm{i}} \text { sent } t_{\text {(picture of himself } \mathrm{f}_{\mathrm{j}} \mathrm{j}}\right] \text {. }
\end{aligned}
$$

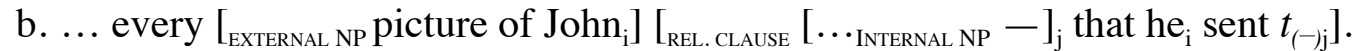

On the assumption that both types of structure are available in principle, we assume that ordinary relative clauses are structurally ambiguous. However, for a relative clause like the one in (16)a with an anaphor inside the head NP, an externally headed structure like (17)b is unavailable, blocked by the impossibility of satisfying Condition A. Conversely, a relative clause like the one in (16)b cannot have a (purely) internally headed structure as in (17)a, owing to the copy of the $\mathrm{R}$-expression in the trace position which would be expected to result in a Condition $\mathrm{C}$ violation.

FIRs show the same kinds of reconstruction effects that finite relative clauses do, as can be seen in (18). We take this to indicate that they, too, can in principle be either of the raising or matching kind.

\footnotetext{
${ }^{13}$ The NP containing the anaphor then is at the head of a chain internal to the relative clause. Consequently, the anaphor is expected to be able to find an antecedent local to the trace position, in accord with observations of Barss (1986). We follow others (e.g. Chomsky 1993, Fox 1999) in assuming that Barss' generalization results from the copy theory of movement, although nothing here hinges on this assumption.

${ }^{14}$ Whether matching relative clauses also have an identical NP (modulo Vehicle Change of the proper name [Fiengo \& May 1994]) inside the relative clause (hence the label "matching") or simply a null operator is orthogonal to our argument.
} 
(18) a. Mary saw a picture of himself for $\mathrm{John}_{\mathrm{i}}$ to send to his parents.

b. Mary saw a picture of $\mathrm{John}_{\mathrm{i}}$ for him $\mathrm{i}$ to send to his parents.

However, as stated in the RMG and unlike their finite counterparts, FIRs display a sensitivity to the difference between raising and matching structures with regard to their modal interpretation. Specifically, only raising FIRs allow for a COULD-reading. We present three sets of data in support of this claim: obligatory reconstruction effects, Condition A effects with matrix antecedents, and extraposition effects.

A. Obligatory Reconstruction Effects with FIRs: We have seen that run of the mill relative clauses can either have a raising or matching structure depending on the specific needs at hand. The RMG however, leads us to expect that FIRs will be more constrained. Specifically, we expect FIRs under the COULD-reading (but not under the $S H O U L D$-reading) to yield obligatory reconstruction effects. That is, we expect the COULD-reading to disappear whenever a raising structure is unavailable. Thus, an FIR for which reconstruction of the head NP would yield a Condition $\mathrm{C}$ violation is expected to lack a COULD-reading. In contrast the SHOULD-reading is expected to be unaffected in such environments. We illustrate this in (19).

(19) a. There are many facts about $\mathrm{John}_{\mathrm{i}}$ for him $\mathrm{i}_{\mathrm{i}}$ to tell his superiors

... \#if he wants to impress them.

... and so he'd better get started.

There are many things about John that he $_{i}$.

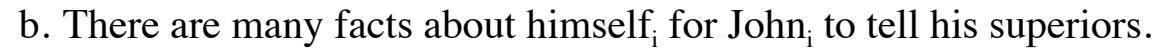

$\ldots$ if he wants to impress them.

... and so he'd better get started.

There are many facts about himself that $\mathrm{John}_{i}$ could/should tell his superiors ...

The FIR in (19)a has only a $S H O U L D$-reading, if John and him are understood as co-referential. According to the RMG, this is because the (purely internally-headed) raising structure is unavailable: reconstruction of the head NP facts about John would yield a Condition C violation. If we replace the pronoun with an anaphor and reverse the order of the anaphor and the Rexpression, as in (19)b, reconstruction is possible (in fact necessary to satisfy Condition A) and the FIR can have either a COULD- or a $S H O U L D$-reading. ${ }^{15}$

A particularly striking illustration can be given with FIRs in which the SHOULD-reading is structurally determined through an anti-reconstruction environment while at the same time pragmatically disfavored. The contrast in (20)a,b is an example of this sort. ${ }^{16}$

\footnotetext{
15 Judgments about reconstruction effects are known to be subtle and moreover subject to some variation across speakers. We believe, however, that these correlations hold. That is, to the extent that speakers get basic reconstruction effects with relative clauses (e.g. Condition $\mathrm{C}$ violations) they also judge that the COULD-reading disappears when reconstruction is not possible.

${ }^{16}$ All capital letters is used here to indicate phonological prominence.
} 
(20) SPEAKER A: It is very difficult for a potential bride to gain the approval of Norman's mother. In fact, she probably thinks there aren't any women at all who are good enough for him.

SPEAKER B: That's not what she thinks...

a. \#She thinks there are several friends of Norman ${ }_{\mathrm{i}}$ 's DOCTOR for him $\mathrm{i}_{\mathrm{i}}$ to marry. ... there are several friends of his doctor that Norman could/\#should marry.

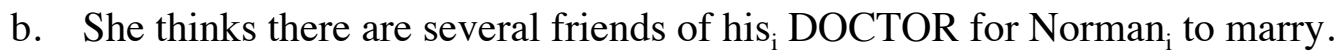
... there are several friends of Norman's doctor that he could/\#should marry.

Since Norman would not plausibly be expected to marry more than one friend of his doctor, the SHOULD-reading is pragmatically disfavored in (20)a,b and only the COULD-reading is sensible. The COULD-reading is, however, precluded in (20)a because the internally headed structure, sketched in (21)a, is required to generate it (in accord with the RMG), and this structure would yield a condition $C$ violation. The only available structure for (20)a, then, is the externally headed (21)b, which - according to the RMG - is compatible only with the SHOULD-reading.

(21) a. *... several $\left[\left[\cdots_{\text {Internal NP }} \text { friends of } \text { Norman }_{\mathrm{i}} \text { 's doctor }\right]_{\mathrm{j}}\right.$ for him $\mathrm{i}_{\mathrm{i}}$ to marry $\left.t_{\left(\text {friends of } N_{i} \text { 's doctor }\right) \mathrm{j}}\right]$.

b. \#... several $\left[_{\text {EXTERnAL NP }} \text { friends of } \text { Norman }_{\mathrm{i}}{ }^{\prime} \text { s doctor }\right]_{\mathrm{j}}\left[[\cdots \text { internal NP }-]_{\mathrm{j}}\right.$ for him $\mathrm{i}_{\mathrm{i}}$ to marry $\left.t_{(-) \mathrm{j}}\right]$.

(20)a therefore produces the same oddness that we observed in sentences like (6)b. In (20)b, on the other hand, reconstruction is possible - i.e. the internally headed structure in (22) is not blocked by any binding condition - and consequently the sentence is felicitous.

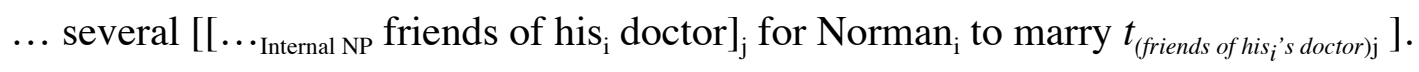

This pattern is quite surprising in light of the fact that reconstruction is, in general, optional and not obligatory in relative clauses. Indeed, the finite paraphrases of our FIRs do not display a dependency between the possibility/necessity of reconstruction and modal force, (23).

(23) a. There are many facts about himself $\mathrm{i}_{\mathrm{i}}$ that $\mathrm{John}_{\mathrm{i}}$ could/should tell his superiors.

b. There are many facts about $\mathrm{John}_{\mathrm{i}}$ that he $\mathrm{i}_{\mathrm{i}}$ could/should tell his superiors.

B. Condition A Effects with FIRs: Given the RMG, we expect FIRs to give rise to the COULDreading only if they have a raising structure. Since in a raising structure, the head NP is interpreted inside the relative clause, an anaphor inside the head NP might not be close enough to be bound by a matrix antecedent (i.e. it might not satisfy the locality requirement imposed by Condition A).$^{17}$ If so, then we would expect the COULD-reading to be unavailable when the head of an FIR contains an anaphor whose antecedent is a matrix binder. In that situation, a matching

\footnotetext{
${ }^{17}$ Specifically, in a (purely) internally headed structure like (i), we expect the anaphor to be too deeply embedded to take the matrix antecedent. In contrast, an anaphor in an NP that is external to the relative clause as in (ii) can be bound by the matrix antecedent:

(i) MATRIX ANTECEDENT $T_{i} \ldots$ [DP Determiner [REL. CLAUSE $\left[\cdots\right.$ Internal NP $\ldots$ anaphor $\left.r_{i}\right] .$.

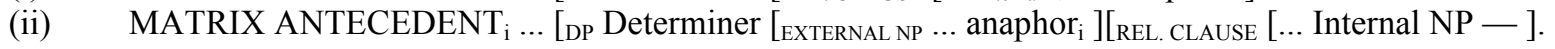


structure would be forced - in turn forcing the SHOULD-reading. (25) shows that this expectation is indeed borne out. The head NP contains a reflexive pronoun whose antecedent is in the matrix clause. This forces the head NP to be interpreted external to the FIR, which, in turn, disambiguates the FIR toward the $S H O U L D$-reading. The COULD-reading reappears if we replace the reflexive with a normal pronoun, (24).

(24) There seem to the boss $\mathrm{i}_{\mathrm{i}}$ to be many stories about him $\mathrm{i}_{\mathrm{i}}$ for you to write up.

...if you feel like writing something for the newsletter.

....if you're interested in keeping your job.

There seem to the boss to be many stories about himself that you could/should write up.

(25) There seem to the boss ${ }_{\mathrm{i}}$ to be many stories about himself for you to write up, \# ...if you feel like writing something for the newsletter.

...if you're interested in keeping your job.

There seem to the boss to be many stories about himself that you could/should write up.

Again, we can observe that the correlation between satisfying Condition A external to the relative clause and existential/universal modal force inside the relative clause holds only for FIRs. That is, finite counterparts of our FIRs can be of the should or could variety irrespective of an anaphor on the NP that is bound by an antecedent in the matrix.

(26) a. There seem to the boss $\mathrm{i}_{\mathrm{i}}$ to be many stories about him $\mathrm{i}_{\mathrm{i}}$ that you could/should write up.

b. There seem to the boss $s_{i}$ to be many stories about himself $f_{i}$ that you could/should write up.

C. Extraposition Effects with FIRs: Extraposition of a relative clause is possible only if the relative clause has a matching structure (Hulsey \& Sauerland 2006; among others). This can be seen, for instance, in the unacceptability of (27)a, which features a Condition A violation due to the fact that reconstruction of the head NP picture of himself is blocked by extraposition.

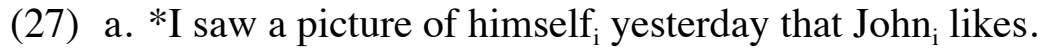

b. I saw a picture of him $_{\mathrm{i}}$ yesterday that $\mathrm{John}_{\mathrm{i}}$ likes.

FIRs can be extraposed just like finite relative clauses. However, given the fact that extraposition blocks raising and our argument that the COULD-interpretation requires a raising structure, we expect the COULD-reading to be unavailable for extraposed FIRs and the SHOULD-reading to be unaffected. This expectation is again borne out as can be seen in (28).

(28) a. \# Joe spotted some cigarettes just now for you to smoke. Joe spotted some cigarettes just now that you could/\#should smoke.

b. Joe just spotted some cigarettes for you to smoke. Joe just spotted some cigarettes that you could/\#should smoke.

As before, finite counterparts of our FIRs behave differently. In particular, extraposing a finite modal relative clause has no effect on the availability of weak modal force: 
The exraposition data, then, as well as the Condition C and Condition A effects we saw above, suggest that the modal force of FIRs is dependent on their structural make-up. Specifically, our observations suggest that the COULD-reading is available only for FIRs that have a head-internal (raising) structure while the SHOULD-reading is compatible with both raising and matching structures (the RMG). This dependency is rather surprising since the quantificational force of a modal clause is not known to depend on the location in which an NP is interpreted. NPs and modal operators do, of course, interact - for instance in de dicto/de re ambiguities. However, in such cases it is the meaning of the NP that varies depending on the structural relation between the modal operator and the NP, and not, as is seemingly the case here, the meaning of the modal operator. In fact, quite generally, there is no obvious way in which an NP could affect the quantificational force of a modal operator. We can see this again by simply observing that the finite counterparts of our FIRs can express both existential and universal force irrespective of whether a raising structure is used.

\section{Summary}

We began this squib with the observation that for-infinitival relative clauses are ambiguous between two distinct readings, which can be distinguished by their modal force (COULD vs. SHOULD). This immediately raises the question of the source of the modal interpretations in FIRs. Are there two different (covert) operators that are selected depending on environmental properties? Or is there, instead, a single modal operator that is inherent to FIRs - one that gives rise to one of the readings in the default case but is subject to a shift of some kind depending on properties of the external environment?

While we did not attempt to derive the modal ambiguity inherent to FIRs, we did present a set of facts that, we think, ought to constrain the solution space. Specifically, we argued for two rather striking generalizations involving unexpected constraints on the choice of modal interpretation. First, the modal force internal to the FIR is constrained by the strength of the determiner (the DMG) - in particular, the COULD-reading requires a weak determiner. Second, the COULD-reading is possible only when the FIR has an internally-headed, raising structure and does not modify a matching external NP (the RMG).

These generalizations are surprising. Why should (and how could) the force of a covert modal operator embedded in an FIR be influenced by, on the one hand, a syntactically remote lexical item (the determiner external to the FIR), and on the other, the presence or absence of an external NP? One obvious question to ask is whether the puzzles are linked - that is, whether they both stem from a single source. The DMG and the RMG do not appear to have much in common, at least superficially. However, we think it is telling that both generalizations involve constraints specific to the COULD-reading. While the SHOULD-reading is possible with any type of determiner and with either a raising or a matching structure, COULD-readings require weak readings of weak determiners, and no external NP. This at least suggests that the SHOULD-reading is the default one, while the COULD-reading arises in a very specialized syntactic and semantic environment. 


\section{$\underline{\text { References }}$}

Bach, E. (1982): "Purpose clauses and control," in P. Jacobson and G. K. Pullum (eds.) The Nature of Syntactic Representation, Dordrecht: D. Reidel, pp. 35-57.

Barss, A. (1986): Chains and anaphoric dependence: on reconstruction and its implications. PhD dissertaion, MIT: MITWPL.

Bhatt, R. (2002): "The raising analysis of relative clauses: evidence from adjectival modification", in Natural Language Semantics 10: 43-90.

Bhatt, R. (2006): Covert modality in non-finite contexts, Mouton de Gruyter.

Bresnan, J. (1972): Theory of Complementation in English Syntax, PhD dissertation, MIT: MITWPL.

Carlson, G. (1977): Reference to Kinds, unpublished PhD. dissertation, University of Massachusetts at Amherst.

Chomsky, N. (1993): “A Minimalist Program for Linguistic Theory,” in Hale, K. and S. J. Keyser (eds.) The View From Building 20, Cambridge, MA: MIT Press.

Diesing, M. (1992): Indefinites, Cambrdige, MA: MIT Press.

Faraci, R. (1974): Aspects of the Grammar of Infinitives and For-phrases. PhD. dissertation, MIT: MITWPL.

Fiengo, R., and R. May (1994): Indices and Identity, Cambridge, MA: MIT Press.

Von Fintel, K. and Iatridou, S. (2007): “Anatomy of a Modal Construction”. Linguistic Inquiry 38(3): 445-483

Fox, D. (1999): "Reconstruction, Variable Binding and the Interpretations of Chains, Linguistic Inquiry 30: 157-196.

Freeze, R. (1992): "Existentials and other locatives.” Language 68: 553-595.

Grosu, A. and F. Landman (1998): "Strange relatives of the third kind", Natural Language Semantics 6: 125-170.

Huettner, A. (1989): Adjunct Infinitives in English, unpublished PhD. dissertation, University of Massachusetts at Amherst.

Hulsey, S. and U. Sauerland (2006): "Sorting out relative clauses", in Natural Language Semantics 14: 111-137.

Iatridou, S. (1996): "To Have and Have not: on the Deconstruction Approach" in Camacho, J., Choueiri, L., and Watanabe, M. (eds.): Proceedings of the $14^{\text {th }}$ West Coast Conference in Formal Linguistics (WCCFL 14), CSLI Publications: 185-200.

Johnson, Kyle, and Satoshi Tomioka. 1998. Lowering and mid-size clauses. In Proceedings of the 1997 Tu“bingen workshop on reconstruction, ed. Graham Katz, Shin-Sook Kim, and Winhart Haike, 185-206. Tuebingen, Germany: Sprachteoretische Grundlagen fuer die Computer Linguistik.

Jones, C. (1985): Syntax and Thematics of Infinitival Adjuncts. PhD. dissertation, University of Massachusetts at Amherst: GLSA.

Kayne, R. (1994): The Antisymmetry of Syntax, Linguistic Inquiry Monographs 25, Cambridge MA: MIT Press.

Kjellmer, G. (1975): “Are Relative Infinitives Modal?” Studia Neophilologica Vol. XLVII No. 2, pp. 323-332.

Koster-Moeller, J. and M. Hackl (2008): “Quantifier scope constraints in ACD: Implications for the syntax of relative clauses”. In N. Abner \& J. Bishop (eds.), Proceedings of the 27th 
West Coast Conference on Formal Linguistics. Somerville, MA: Cascadilla Proceedings Project, 301-309.

Kratzer, A. (1978): Semantik der Rede. Kontext theorie, Modal Woerter, Konditionale, Koenigstein: Scriptor.

Kratzer. A. (1981): “The Notional Category of Modality,” in Eikmeyer,H.,Rieser,H.(eds.):

Words, Worlds and Kontext, Berlin, New York: Walter De Gruyter: 825-834.

Kratzer, A. (1995): "Stage-Level and Individual Level Predicates," Carlson,G. and F. Pelletier (eds.): The Generic Book, Chicago: University of Chicago Press: 125-175.

Milsark, G. (1974): Existential Sentences in English, PhD. dissertation, MIT.

Milsark, G. (1977): "Toward an Explanation of Certain Peculiarities of the Existential Construction in English," Linguistic Analysis 3, 1-29.

McNally, L. and Van Geenhoven, V. (1998): "Redefining the weak/strong distinction." Paper presented at the 1997 Paris Syntax and Semantics Colloquium.

Pesetsky, D. (1992): Zero Syntax II, ms. MIT http://mit.edu/linguistics/www/pesetsky.home.html

Portner, P. (1992): Situation Theory and the Semantics of Propositional Expressions, PhD. dissertation, University of Massachusetts at Amherst: GLSA.

Portner, P. (1997): "The Semantics of Mood, Complementation and Conversational Force," Natural Language Semantics 5: 167-212.

Portner, P. (2009): Modality, Oxford University Press.

Sauerland, U. (1998): The Meaning of Chains, PhD. dissertation, MIT: MITWPL.

Stowell, T. (1982): “The Tense of Infinitives." Linguistic Inquiry 13.3:561-70

Van Geenhoven, V. (1998): Semantic Incorporation and Indefinite Descriptions: Semantic and Syntactic Aspects of Noun Incorporation in West Greenlandic. Stanford, CA: CSLI Publications.

Vergnaud, J.-R. (1974): French Relative Clauses, PhD. dissertation, MIT.

Williams, E. (1983): “Against Small Clauses,” Linguistic Inquiry 14.2: 287-308

Williamson, J. (1987): “An Indefiniteness Restriction for Relative Clauses in Lakhota," in Reuland, E. and A. ter Meulen (eds.): The Representation of (In)definiteness, Cambridge, MA: MIT Press. 